\title{
Peran Sektor Bisnis Dalam Penandatanganan Voluntary Partnership Agreement On Forest Law Enforcement Governance And Trade (Vpa-Flegt) antara Indonesia dan Uni Eropa
}

\author{
Indrawati, MA
}

\begin{abstract}
Abstrak
Tulisan ini akan membahas mengenai peran pihak swasta yaitu pengusaha dalam penandatangan perjanjian kerjasama VPA-FLEGT Voluntary Partnership Agreement On Forest Law Enforcement Governance And Trade antara Uni Eropa dan Indonesia. Kerjasama ini merupakan kerjasama ekonomi yang berbasis pada sertifikasi ramah lingkungan yang diterapkan pada produk kayu yang akan masuk dalam pasar Uni Eropa. Untuk itu, kerjasama ini sangat penting bagi Indonesia mengingat bahwa Uni Eropa merupakan salah satu pasar kayu Indonesia. Peran Pengusaha sendiri sangat penting dalam proses kesepakatan ini, karena pengusaha merupakan ujung tombak dari kebijakan yang nantinya diterapkan. Pemerintah melibatkan pengusaha dalam pelaksanaan diplomasinya terhadap Uni Eropa. Pelibatan pengusaha dapat membantu pemerintah Indonesia dalam meyakinkan Uni Eropa bahwa Indonesia telah siap bergabung dalam kerjasama tersebut. Kata kunci : VPA-FLEGT, pengusaha, kerjasama, diplomasi, lingkungan
\end{abstract}

\section{Pendahuluan}

Kebijakan kerjasama VPA-FLEGT atau (Voluntary Partnership Agreement on Forest Law Enforcement Governance And Trade) yang dikeluarkan oleh Uni Eropa memiliki dampak yang besar bagi negara -negara pengeksport kayu, tidak terkecuali Indonesia. Hal ini karena kebijakan kerjasama tersebut mewajibkan seluruh negara-negara pengeksport kayu dan produk kayu ke Uni Eropa memiliki sistem sertifikasi kayu. Sertifikasi kayu ini dimaksudkan agar seluruh kayu dan produk kayu yang masuk ke Uni Eropa terjamin sebagai produk yang ramah lingkungan. 
Sertifikasi kayu ramah lingkungan diwajibkan kepada seluruh Negara yang ingin memasarkan kayu dan produk kayunya ke Uni Eropa. Lalu bagaimana dengan Negara-negara yang belum memiliki sistem setrifikasi?. Uni Eropa menjawabnya dengan kerjasama VPA-FLEGT, yaitu Uni Eropa akan membantu Negara-negara tersebut untuk dapat membangun sistem sertifikasi. Namun bagi Negara-negara yang telah memiliki sistem sertifikasi tidaklah dengan serta merta dapat bekerjasama dengan Uni Eropa dalam VPA-FLEGT atau terjamin kayu dan produk kayunya masuk ke pasar Uni Eropa. Sistem sertifikasi yang telah dimiliki tersebut harus sesuai dengan standar yang telah ditetapkan Uni Eropa.

Dengan bekerjasama dalam VPA-FLEGT, Uni Eropa menjamin kayu dan produk kayu yang berasal dari negara-negara tersebut dapat masuk dengan mudah ke pasar Uni Eropa. Kayu dan Produk kayu yang berasal dari Negara yang telah bekerjasama tersebut tidak perlu melalui tahap pemeriksaan kelegalan oleh Uni Eropa.

Indonesia sebagai Negara dimana kayu dan produk kayu merupakan salah satu produk eksport terbesar telah membangun Sistem Sertifikasi Kayu sejak tahun 2003. Namun, bukan berarti kayu dan produk kayu asal Indonesia dapat melenggang tanpa hambatan dipasar Uni Eropa. Indonesia harus meyakinkan Uni Eropa bahwa sistem sertfikasi yang telah dibangunnya telah sesuai dengan sistem sertifikasi yang dimiliki Uni Eropa. Pada saat sistem sertifikasi kayu tersebut telah diakui dan sesuai dengan sistem sertifikasi Uni Eropa, maka Indonesia dapat beranjak ke fase penandatangan kerjasama VPA-FLEGT.

Kerjasama VPA-FLEGT ini dianggap sebagai kerjasama yang penting bagi Indonesia, Hal ini tidak lain karana Uni Eropa merupakan pasar kayu dan produk kayu Indonesia yang potensial. Dukungan berbagai pihak sangat diperlukan dalam proses ini tidak terkecuali pihak pengusaha atau bisnis. Karena para pengusaha ini merupakan ujung tombak perdagangan internasional. Lalu bagaimanakah peran para pengusaha Indonesia dalam proses perumusan sistem sertifikasi? Bagaimana pula peran pengusaha dalam meyakinkan Uni Eropa agar segera dapat bekerjasama dengan Indonesia dalam VPA-FLEGT? 


\section{Kerangka Konseptual}

\section{Kerjasama Internasional}

Menurut K.J. Holsti, kerjasama internasional dapat didefinisikan dalam lima aspek. Pertama, pandangan bahwa dua atau lebih kepentingan, nilai atau tujuan saling bertemu dan dapat menghasilkan sesuatu, dipromosikan atau dipenuhi oleh semua pihak sekaligus. Kedua, pandangan atau harapan dari suatu negara bahwa kebijakan yang diputuskan oleh negara lainnya akan membantu negara itu untuk mencapai kepentingan dan nilai-nilai. Ketiga, persetujuan atau masalah-masalah tertentu antara dua negara atau lebih dalam rangka memanfaatkan persamaan kepentingan atau benturan kepentingan. Keempat, aturan resmi atau tidak resmi mengenai transaksi di masa depan yang dilakukan untuk melaksanakan persetujuan. Yang terakhir, transaksi antarnegara untuk memenuhi persetujuan mereka (Mugasejati, 2006).

Kerjasama dapat terjadi dimana tindakan para aktor mengarah pada satu kebersamaan melalui proses negosiasi. Kerjasama terjadi ketika para aktor saling melakukan penyesuaian tindakan melalui proses koordinasi (Mugasejati \& Rais, Politik Kerjasama Internasional: Sebuah Pengantar, 2011).

\section{Diplomasi Bisnis}

Upaya pemerintah untuk meyakinkan pihak lain demi tercapainya kepentingannya dengan cara-cara damai disebut dengan diplomasi. Diplomasi dapat dilakukan oleh berbagai pihak dan tidak selalu dilakukan oleh pemerintah. Peran berbagai pihak dalam diplomasi ini sering disebut dengan multitrack diplomacy. Dalam multitrack diplomacy, dijelaskan bahawa ada Sembilan actor yang dapat melakukan diplomasi. Salah satunya adalah Bisnis yang berada dalam track ketiga.

Track ketiga menjelaskan bahwa diplomasi dapat dilakukan oleh perusahaan ataupun para pembisnis yang berkepentingan dalam isu yang sedang dibicarakan atau dinegosiasikan. Dalam diplomasi sector ini biasanya terjadi karena isu yang dibicaran berkaitan dengan perdagangan dan urusan ekonomi. 
Pemerintah melibatkan sector bisnis, karena sector bisnis dianggap dapat membantu keberhasilan tercapainya kepentingan Negara. Isu yang sedang dibahaspun berhubungan dengan kebijakan perdagangan dan hubungan kerjasama dengan Negara lain. Selain membawa kepentingan Negara, biasanya para pembisnis ini juga membawa kepentingan pribadi mereka, yaitu perluasan bisnis. Kepentingan ekspansi pasar pencarian sumber daya atau bahan baku menjadi alasan perusahaan melakukan diplomasi. (McDonald., 1996)

\section{Pembahasan}

\section{Kerjasama VPA-FLEGT}

Kebijakan sertifikasi ramah lingkungan marak diterapkan banyak Negara terhadap barang-barang import mereka yang berbasis pada alam. Uni Eropa menjadi salah satu organisasi internasional yang menerapkan kebijakan ramah lingkungan. Kebijakan ramah lingkungan tersebut satlah satunya diberlakukan pada kayu dan produk kayu. Kebijakan Uni eropa tersebut dikeluarkan dalam FLEGT (Forest Law Enforcement Governance dan Trade).

FLEGT merupakan kebijakan yang diterapkan oleh Uni Eropa dimana mengharuskan semua produk kayu yang masuk ke Uni Eropa memiliki sertifikasi legal. Gagasan mengenai kebijakan ini telah dimulai sejak 2001 dimana pada September 2001. Kebijakan ini merupakan upaya penyelamatan lingkungan oleh Uni Eropa yang terkait dengan perdagangan. Penyelamatan lingkungannya dalam bentuk memberantas illegal logging, sedangkan kaitannya dengan perdagangan yaitu mengatasi perdagangan kayu ilegal secara global. Komitmen Uni Eropa itu disampaikan pada pertemuan puncak dunia untuk pembangunan berkelanjutan (The World Summit on Sustainable Development) di Johannesburg tahun 2002 yang kemudian ditindaklanjuti dengan FLEGT Action Plan pada bulan Mei 2003 (EU response - FLEGT action plan).

Untuk melaksanakan kebijakan FLEGT kemudian Uni Eropa membuat VPA atau Voluntary Partnership Agreemant yang merupakan action plan dari FLEGT. 
VPA berbentuk perjanjian kerjasama antara Uni Eropa dengan negara produsen kayu. Kerjasama dipilih sebagai upaya Uni Eropa mengatasi kerusakan lingkungan karena kerjasama lingkungan internasional memainkan peran yang penting dalam menangani masalah kerusakan lingkungan. Masalah lingkungan ini tidak hanya menjadi masalah domestik tapi sudah menjadi masalah internasional karena dampaknya dapat terjadi lintas batas negara. Untuk mengatasi masalah lingkungan lintas batas ini membutuhkan kerjasama internasional antara penyebabnya dan yang mendapat dampaknya (Buck, 2007).

VPA diperkenalkan oleh Uni Eropa melalui peraturan (EC) No. 2173/2005 yang merupakan mekanisme untuk mengidentifikasi dan mengeluarkan kayu ilegal dari pasar Uni Eropa (Hawin, Nurhayati, \& Antoni, 2010). Elemen kunci dalam VPA adalah untuk mendorong negara mitra mengembangakan sistem administrasi dan teknis legalitas yang kredibel untuk memverifikasi kayu berdasarkan hukum (Heeswijk \& Turnhout, 2013). Sistem Administrasi tersebut dinamakan TLAS atau Timber Legallity Anssurance System.

Dengan kerjasama yang diinisiasi oleh Uni Eropa melalui VPA, diharapkan negera-negara mitra dapat mengembanggakan pengelolaan hutan yang lebih baik. tujuan Uni Eropa ini diwujudkan dengan menyediakan dukungan dan bantuan dalam membangun dan menyempurnakan sistem verifikasi legalitas kayu di negara-negara mitra tersebut (Hawin, Nurhayati, \& Antoni, 2010).

Pemberlakuan kebijakan FLEGT sebagai salah satu kebijakan sertifikasi pada pasar kayu Uni Eropa tentunya akan sangat berdampak pada negara-negara eksportir kayu, salah satunya Indonesia. Untuk menghindari dampak ditolaknya produk Indonesia di pasar Uni Eropa, kemudian Indonesia mulai bekerjasama dalam VPA. Uni Eropa merupakan salah satu pasar yang potensial bagi kayu dan produk kayu Indonesia. Tujuan utama kayu Indonesia di pasar Uni Eropa yaitu Jerman, Inggris, Belanda, Belgia, Prancis, Spanyol dan Italia (European and Indonesian experts to inform, 2011). 
Gambar 1.2 Nilai ekspor kayu Indonesia ke Uni Eropa

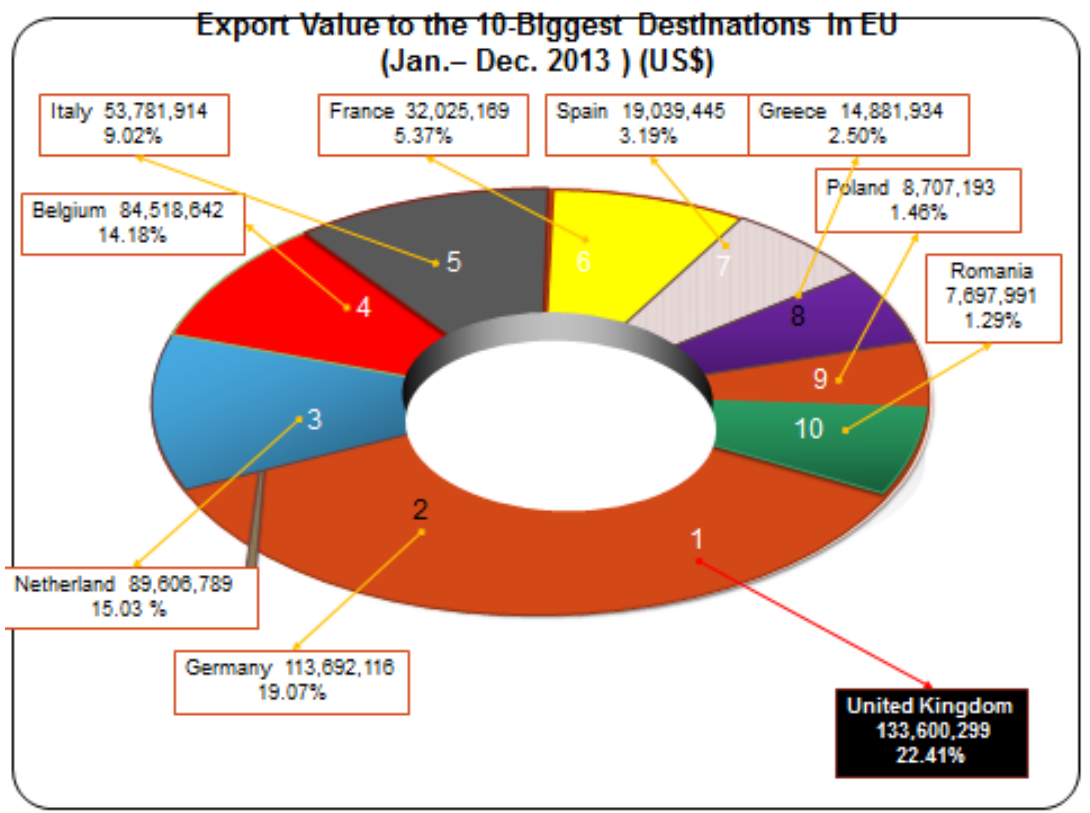

Sumber: Bina Pengolahan dan Pemasaran Hasil Hutan

(Sudharto, 2012)

Kenyataan bahwa pasar Uni Eropa memberi kontrinusi yang cukup besar bagi kayu Indonesia, membuat Indonesia akan sangat merasakan dampak dari penerapan kebijakan FLEGT. Untuk itu, kemudian Indonesia sepakat untuk masuk dalam pembicaraan perjanjian ini setelah melakukan serangkaian konsultasi publik. Konsultasi publik ini dilakukan oleh pemerintah Indonesia tidak lain karena Indonesia sedang mengembangkan good governance di sektor kehutannanya.

Perhatian Uni Eropa untuk menghalangi masuknya produk kayu yang dipanen dengan tidak legal selain dengan FLEGT juga ditunjukkan dengan pemberlakuan The EU Timber Regulation (EUTR). EUTR sendiri telah diberlakukan pada tahun 2013. Dengan pemberlakuan EUTR, Uni Eropa menjatuhkan sanksi serius pada importir membawa kayu ilegal ke dalam Pasar Eropa. Importir akan diminta untuk melakukan due diligence dan risiko mitigasi untuk memastikan bahwa produk yang mereka impor berasal dari kayu yang dipanen secara legal 
(Mandelson, 2012). Due dilligence merupakan suatu sistem untuk menilai resiko dari kayu atau produk kayu dari suatu sumber yang ilegal. Pengujian produk kayu dengan sistem due dilligence dilakukan di Uni Eropa. Pengujian due dilligence memiliki resiko tinggi karena jika produk tersebut tidak lolos uji maka harus dikembalikan ke negara asal yang tentunya menambah biaya lagi. Namun, peraturan tersebut akan tidak berlaku pada negara-negara yang telah bekerjasama dalam VPA. Uni Eropa akan secara efektif menghilangkan peraturan tersebut kepada negara-negara mitra VPAnya.

VPA dianggap sebagai cara lain untuk meyakinkan pembeli, pembuat kebijakan dan organisasi non pemerintah bahwa kayu yang diekspor ke Uni Eropa dari Indonesia merupakan kayu yang dipanen secara legal. Perjanjian ini juga mendorong reformasi jangka panjang pada pengelolaan hutan di Indonesia (Mandelson, 2012). VPA dianggap sebagai kesempatan untuk mendorong reformasi dalam pengelolaan sumber daya hutan dan kunci dalam pengolahan lingkungan yang lebih baik. Penandatanganan VPA akan memberi keuntungan bagi Indonesia dengan membantu industri kayu memperkuat posisi pasar di Uni Eropa dan ditempat lain. Selain itu, membantu mengelola sumber hutan dengan cara yang berkelanjutan. Masih ada beberapa keuntungan lain yang akan didapat dari penandatanganan VPA ini diantaranya:

1. Menghindari sistem Due Dillegent

Sistem Due dilligence atau uji tuntas merupakan suatu sistem yang berfungsi untuk memastikan bahawa kayu atau produk kayu yang masuk ke Uni Eropa berasal dari suatu sumber yang legal. Due dilligent mengatur mengenai kewajiban zero risk pada operator pertama dan kewajiban duty of care bagi subseq Uni Eropant operator (Hawin, Nurhayati, \& Antoni, 2010). SubseqUni Eropant operator adalah internal trader.

Pengujian produk kayu dengan sistem due dilligent dilakukan di Uni Eropa. Namun jika telah bekerjasama dalam VPA, pengujian produk dilakukan menggunakan aturan negara produsen di negaranya masingmasing. Hal ini berarti negara yang tidak bekerjasama dalam VPA memiliki 
resiko yang lebih tinggi karena proses ujinya dilakukan di Uni Eropa. Resiko tinggi tersebut adalah jika produk tersebut tidak lolos uji maka harus dikembalikan ke negara asal yang tentunya menambah biaya lagi.

Setelah Indonesia resmi bekerjasama dalam VPA maka seluruh ekspor produk kayu yang berlisensi dari Indonesia akan diterima sebagai produk legal (zero risk) sesuai dengan aturan EU Timber Regulation dan tidak akan melalui proses due diligence untuk memasuki pasar Uni Eropa (Departemen Kehutanan, 2013). Nantinya jika VPA sudah berjalan, maka kayu Indonesia dengan sertifikat SVLK akan diterima pasar Uni Eropa tanpa terlebih dahulu dilakukan due-diligence atau zero-risk.

2. Meningkatkan ekspor kayu Indonesia

Setelah bekerjasama dengan Uni Eropa dalam VPA-FLEGT, maka semua produk kayu Indonesia akan mendapatkan lisensi FLEGT. Lisensi FLEGT yang didapat kayu dan produk kayu asal Indonesia berdampak pada diakuinya kayu asal Indonesia sebagai produk yang legal. Hal ini pun akan dapat meningkatkan kepercayaan masyarakat Uni Eropa terhadap kayu Indonesia yang akan mempermudah peningkatan pemasaran produk kayu Indonesia di pasar internasional lainnya.

3. Mendorong perkembangan ekonomi

Dengan meningkatnya ekspor kayu Indonesia ke Uni Eropa secara otomatis akan berdampak pada ekonomi Indonesia secara makro. Peningkatan ekspor juga akan mendorong pertumbuhan ekonomi melalui berkembangnya industri pengolahan hasil hutan, menyediakan lapangan kerja dan meningkatkan kesejahteraan masyarakat.

4. Mengurangi degradasi hutan melalui penebangan liar

Penandatanganan VPA ini akan menjadi alat penegakan hukum tambahan yang diperlukan untuk memberantas kegiatan illegal loggin di Indonesia. Dimana kayu-kayu dengan sumber penebangan illegal tidak akan dapat diekspor ke Uni Eropa. Untuk itu, sektor industri dituntut untuk 
memproduksi kayu secara legal agar produk-produknya tetap dapat di terima di pasar Eropa.

5. Meningkatkan kredibilitas SVLK dan kepercayaan dunia

Dengan ditandatanganinya VPA-FLEGT akan memberikan insentif bagi produk kayu Indonesia karena berarti Uni Eropa mengakui bahwa produk kayu Indonesia serta Sistem verifikasi Indonesia kredibel dan dapat dipercaya. Selain itu Uni Eropa juga mengakui bahwa Sistem Verifikasi kayu Indonesia atau SVLK yang telah dikembangkan sejak tahun 2003 telah memenuhi prinsip legal sebagaimana dimaksud dalam EU Timber Regulation. Dengan diakuinya SVLK oleh Uni Eropa akan berdampak pada kepercayaan dunia terhadap sistem yang ada di Indonesia. Karenanya, VPAFLEGT merupakan rekognisi atas SVLK Indonesia dan hal ini menaikkan reputasi produk perkayuan Indonesia

Walaupun Uni Eropa hanya 10\% dari pasar kayu Indonesia, namun pemangku kepentingan kehutanan Indonesia menyadari bahwa ketika Eropa menerima SVLK (melalui implementasi VPA), akan jauh lebih mudah bagi Indonesia untuk juga "memaksa" pasar lain untuk juga menerima SVLK sebagai sistem penjaminan legalitas yang kredibel.

Dengan penandatanganan VPA dan implementasinya kemudian, maka Pemerintah Indonesia akan dikenal sebagai salah satu pemerintah yang aktif dalam mempromosikan dan memberantas tindakan illegal logging yang sangat merugikan bagi Indonesia, juga masyarakat dunia. Dalam bidang perdagangan kayu, produk kayu Indonesia akan dikenal sebagai kayu legal, yang memenuhi standar mutu dan kualitas yang dipersyaratkan oleh pasar UE (Hawin, Nurhayati, \& Antoni, 2010).

\section{Peran Pengusaha Indonesia dalam Proses Perumusan SVLK}

Kerjasama VPA-FLEGT antara Indonesia dan Uni Eropa akan memberi dampak baik bagi perekonomian Indonesia yang berbasis pada kayu dan produk kayu. Kerjasama ini juaga secara langsung mempengaruhi para pengusaha kayu, oleh 
karena itu pemerintah Indonesia melibatkan para pengusaha kayu ini dalam proses kesepakatan kerjasama dengan Uni Eropa. Penyertaan para pengusaha dalam proses VPA ini dilakukan baik di dalam maupun diluar. Proses di dalam adalah proses pembuatan SVLK sesbagi peraturan Indonesia yang mengatur mengenai legalitas kayu.

Pengusaha merupakan pihak yang nantinya akan menjalankan SVLK, oleh karenanya para pengusaha diharapkan dapat memberi masukan pada perumusan SVLK. Hal ini tidak lain karena merekalah yang nantinya menjalankan sistem ini secara langsung. Pelibatan para pengusaha ini juga ditujukan agar segala kepentingan para pengusaha dapat terakomodir. Salah satu pengusaha yang ikut dalam proses adalah perwakilan dari Asmindo (Asosiasi Pengusaha Mebel Indonesia).

Pemerintah memberikan pelatihan kepada para pengusaha meminta mengenai SVLK. Tujuannya adalah agar para pengusaha paham betul bagaimana menerapkan SVLK dalam industri. Asmindo meminta Pemerintah melalui MFP (Multistakeholder Forestry Programme) untuk mengadakan pelatihan mengenai SVLK terhadap pengusaha kecil dan menegah. Permintaan ini kemudian direspon dengan mengadakan pelatihan dengan tema Pelatian SVLK Bagi Kelompok Usaha Kecil dan Menengah (UKM) Pemegang Izin Usaha Industri Kayu Lanjutan (Furniture, Kerajinan, dll) yang dilaksanakan pada 12 April hingga 12 Mei 2012 (Kementerian Kehutanan Badan Penyuluhan Dan Pengembangan Sdm Kehutanan Pusat Penyuluhan Kehutanan, 2011).

Asmindo juga turut menggandeng WWF untuk mensosialisasikan SVLK. Program kerjasama Asmindo dengan WWF meliputi kerjasama mendukung implementasi Sistem Verifikasi Legalitas Kayu (SVLK) sebagai langkah kunci dalam menciptakan pola produksi dan konsumsi yang bertanggung Jawab dalam industri pengolahan kayu di Indonesia khususnya mebel dan kerajinan. Tujuan dari kerjasama ini adalah mengimplementasikan proyek EU SWITCH ASIA yang mencakup Pulau : Sumatera, Jawa \& Bali serta Kalimantan, dalam memfasilitasi anggota Asmindo yang termasuk dalam kategori Usaha Kecil Menengah (UKM) untuk memperoleh SVLK serta mengembangkan praktek konsumsi dan produksi berkelanjutan pada bidang 
pemanfaatan hasil hutan. Lingkup kegiatan yang akan dilakukan antara lain program pelatihan pendampingan SVLK untuk anggota Asmindo, yang akan dilakukan di 12 kota (Kerjasama Asmindo dan WWF untuk Mendukung Implementasi SVLK, 2013). SWITCH ASIA ini sendiri bertajuk "Promoting The Implementation of Timber Legality Assurance FLEGT License as a Key Step to Sustainable Production and Consumption in Indonesia's wood processing Industry" Kegiatan ini bertujuan meningkatkan kapasitas lebih dari 300 UKM di Indonesia mengenai SVLK selama tiga tahun ke depan. Serta mempromosikan kebijakan pembelian produk-produk hijau bersertifikat SVLK (green procurement policy) di dalam negeri (WWF-Indo, Asmindo, GFTN, Uni Eropa, 2013).

Berbagai sosialisasi ini dilakukan agar SVLK sebagai kebijakan dapat diketahui dan dipahami oleh seluruh lapisan masyarakat khususnya yang berkepentingan di sektor kehutanan. Diharapkan semua pihak di dalam negeri dapat menjalankan dan mengimplementasikan SVLK dengan baik. Jika berbagai pihak didalam negeri telah dapat menjalankan SVLK dengan benar, maka akan memberikan image positif bagi pasar internasional khususnya Uni Eropa. Indonesia akan dinilai sebagai Negara yang telah memiliki tata kelola kehutanan dan lingkungan yang baik.

\section{Peran Pengusaha dalam Proses Penandatangan Kerjasama VPA-FLEGT antara Indonesia dan Uni Eropa}

Peran pengusaha dalam penerapan SVLK secara menyeluruh di Indonesia bertujuan untuk meyakinkan pasar internasional khususnya Uni Eropa bahawa Indonesia adalah produsen kayu dan produk kayu yang legal. Untuk tahapan selanjutnya, pemerintah Indonesia juga melibatkan para pengusaha kayu dalam proses negosiasi kerjasama dengan Uni Eropa. Keikut sertaan pengusaha kayu dalam diplomasi ini kerena perjanjian ini akan sangat memberi dampak besar terhadap para pengusaha kayu tersebut. Jalur Tiga ini memiliki kekuatan besar untuk melakukan perubahan. Dimana Industri-industri baru dan peluang baru biasanya membawa standar dan pertimbangan yang berbeda dengan yang dibawa oleh pemerintah. Untuk 
itu negosiasi yang dilakukan antara kedua belah pihak tentunya diupayakan untuk saling mengkoordinasikan kepentingan masing-masing pihak melalui kesepakan FLEGT. (Indrawati, 2014)

Keterlibatan para pengusaha dalam negosiasi dengan Uni Eropa yaitu dengan dimasukkannya perwakilan pengusaha kayu sebagai bagian dari anggota Delegasi RI (DELRI). Mereka sekaligus menjadi saksi dan praktisi bahwa pengelolaan hutan dan pemrosesan produk kayu Indonesia memenuhi kaidah dan aturan yang berlaku, dan karenanya wajar untuk lulus sertifikasi. Dalam pertemuan tersebut pengusaha diberi kesempatan mengemukakan pendapat dan memberi masukan tentang sistem yang akan dijalankan nantinya. (Indrawati, 2014)

Keterlibatan para pihak salah satunya adalah pada TWG (Technical Working Group ) yang dilaksanakan oleh Uni Eropa dan Indonesia. Berikut gambaran peserta TWG:

Tabel 2.2 Technical Working Group

\begin{tabular}{|l|l|l|}
\hline TWG & Tema & Peserta \\
\hline 1 & Pengembangan kapasitas & $\begin{array}{l}\text { MoF, KAN, LEI, APHI, Komisi Uni } \\
\text { Eropa-Indonesia FLEGT Support } \\
\text { Project dan MFP. }\end{array}$ \\
\hline 2 & Sosialisasi SVLK & $\begin{array}{l}\text { MoF, KAN, Komisi Uni Eropa- } \\
\text { Indonesia FLEGT Support Project, } \\
\text { MFP, TNC dan APHI. }\end{array}$ \\
\hline 3 & Pemantau Independen & $\begin{array}{l}\text { TI Indonesia, Pustanling, MoF, } \\
\text { ISWA, MFP dan Komisi Uni Eropa- } \\
\text { Indonesia FLEGT Support Project. }\end{array}$ \\
\hline
\end{tabular}

Sumber: (Dephut, 2010)

Dari tabel diatas dapat dilihat beragamnya peserta TWG yang berasal dari MoF (Minister of Rorestry), perwakilan Uni Eropa, Asosiasi (APHI, ISWA) serta LSM atau perwakilan masyarakat sipil TNC. 
Pengusaha kayu yang ikut serta dalam pertemuan merupakan wakil dari pengusaha kayu yang telah memenuhi SVLK. Pada saat terjadi deadlock pembicaraan antara Uni Eropa dan Indonesia, pengusaha dapat memberikan masukan yang dapat memecahkan kebuntuan pembicaraan. Penerapan SVLK oleh penguasaha kayu di Indonesia tentunya akan memberikan citra yang baik di mata Uni Eropa yang dalam hal ini sedang melakukan proses negosiasi dengan Indonesia. Tingginya angka industri kayu yang telah bersertifikat akan menggambarkan bahwa Indonesia telah dapat menerapkan sistem sertifikasi. Seperti PT. Jawa Furni lestari atau Java Furniture yang telah mengantongi sertifikasi SVLK. Selain itu PT Riau Andalan Pulp and Paper (RAPP) juga telah mengantongi sertifikat berbasis SVLK yaitu sertifikatsertifikat Pengelolaan Hutan Produksi Lestari untuk hutan tanaman yang dikelolanya dan Sertifikat Legalitas Kayu sejak 2010. Kedua sertifikat tersebut membuktikan kayu yang bersumber dari hutan tanaman RAPP bukan sekedar legal, tetapi juga dari hutan tanaman yang dikelola secara lestari (SILK, 2013).

Kepatuhan pengusaha terhadap SVLK juga ditunjukkan dengan semakin banyaknya hutan produksi di Indonesia yang telah mendapatkan sertifikasi. Dalam kurun waktu 2009 - 2014 sudah sekitar 2 juta hektar hutan produksi yang disertifikasi: PHPL-HT, 63 unit (4.973.287 ha); PHPL-HA, 127 unit (12.534.005 ha); PHPL-KPH, 8 unit (249.227 ha); VLK-HT, 54 unit (1.460.675 ha); VLK-HA, 23 unit (1.658.060 ha); VLK-Hutan Hak, 84 unit (48.665 ha) dan VLK-Industri, 944 unit. Dari jumlah sertifikasi ini setidaknya sudah 198 unit PHPL dan 1105 unit VLK. Sehingga keseluruhan yang tersertifikasi 1,303 unit management (Yayasan Pusaka, 2014).

Dengan telah patuhnya para pengusaha menjalankan SVLK, maka produkproduk yang dihasilkan dapat dipercaya sebagai produk yang legal. Untuk lebih meyakinkan konsumen bahwa produk-produknya merupakan produk legal, para pengusaha ini juga juga ikut berpartisipasi mempromosikan SVLK dengan mengikuti berbagai pameran produk kayu di luar negeri. Seperti yang dilakukan Diraja Surya Furniture dan Istana Kayu Sukses Makmur yang berpartisipasi pada Pameran Domotex di Hannover dalam stand yang difasilitasi oleh (SIPPO) bekerjasama 
dengan Import Promotion Desk (IPD) Jerman pada tanggal 11-14 Januari 2014 (KJRI Hamburg, 2014).

Setelah negosiasi panjang sejak tahun 2007, akhirnya kedubelah pihak sepakat untuk menandatangani perjanjian tersebut. Pada tanggal 30 September 2013 Indonesia-Uni Eropa resmi menandatangani persetujuan penegakan hukum, tata kelola, serta perdagangan bidang kehutanan atau Forest Law Enforcement Governance and Trade - Voluntary Partnership Agreement (FLEGT-VPA) yang dilaksanakan di Markas Besar Uni Eropa di Brussels, Belgia (Prijono, 2013).

\section{Kesimpulan}

Pelibatan berbagai aktor dalam proses meyakinkan Negara lain agar mau bekerjasama dengan Indonesia memberikan dampak yang positif. Dalam proses kesepakatan kerjasama dengan Uni Eropa dalam VPA-FLEGT, Indonesia mengikutsertakan pengusaha atau sector bisnis. Diplomasi yang dilakukan oleh pengusaha atau bisnis ini berada dalam track ketiga dalam konsep multitrack diplomacy.

Pelibatan pengusaha ini tidak hanya pada saat negosiasi langsung dengan Uni Eropa, tetapi juga dalam proses perumusan dan sosialisasi SVLK kepada para pengusaha kayu di Indonesia. Selama proses Negosiasi dengan pihak Uni Eropa, pihak pengusaha dimasukkan dalam tim delegasi Indoneseia bersama pihak lainnya. Perannya adalah menyakinkan Uni Eropa bahwa sistem sertifikasi yang dijalankan oleh Indonesia telah menjalankan sistem pembangunan lingkungan berkelanjutan. Pengusaha Indonesia juga memberikan berbagai masukan selama proses negosiasi.

Selain turut serta dalam proses negosiasi, pengusaha Indonesia juga melakukan berbagai pameran yang memamerkan berbagai produk olahan kayu yang berasal dari kayu legal. Hal ini dilakukan agar Uni Eropa dan pasar internasional yang telah menerapkan sertifikasi ramah lingkungan percaya dan yakin bahwa kayu dan produk kayu asal Indonesia merupakan produk yang legal. 
Keterlibatan pengusaha dalam proses negosiasi dengan Uni Eropa sangat membantu pihak pemerintah Indonesia. Sehingga Uni Eropa yakin bahwa Indonesia telah dapat menjalankan tata kelola hutan yang berkelanjutan sesuai dengan yang diterapkan Uni Eropa.

\section{Daftar Pustaka}

\section{Buku}

Buck, M. (2007). Making EU International Environmental Policy. In N. Bayne, \& S. Woolcock, The New Economic Diplomacy: Decision-making and Negotiation in International Economic Relations (p. 242). Inggris: Asghate Publishing.

Hawin, M., Nurhayati, I., \& Antoni, V. (2010). Analisis Hukum Teks Voluntery Partnership Agreement antara Indonesia dan Eropa. Jakarta: Forest Governancce and Multistakeholder Programme.

McDonald., L. D. (1996). Multitrack Diplomacy: A System Approach and Peace. Connecticut: Kumarian Press.

Mugasejati, N. P., \& Rais, A. H. (2011). Politik Kerjasama Internasional: Sebuah Pengantar. Yogyakarta: International of Institute Studies.

\section{Jurnal}

Heeswijk, 1. v., \& Turnhout, E. (2013). The discursive structure of FLEGT (Forest Law Enforcement, Governance and Trade): The negotiation and interpretation of legality in the EU and Indonesia. Forest Policy and Economics 32, 6-13.

Mandelson, L. P. (2012, october). The EU-Indonesia Voluntary Partnership Agreement: Risks and opportunities. Retrieved Agustus 10, 2014, from strategig review: http://www.sr-indonesia.com/in-the-journal/view/the-euindonesia-voluntary-partnership-agreement-risks-and-opportunities

Mugasejati, N. P. (2006). Legalisasi dalam Politik Kerjasama Internasional. Jurnal Ilmu Sosial dan Ilmu Politik Volume 10, Nomor 2.

\section{Laporan}


Departemen Kehutanan. (2013). Naskah Penjelasan. Jakarta: Departemen Kehutanan. Dephut. (2010). EU-INDONESIA FLEGT VPA EXPERTS MEETING Technical Annex of the 2nd.

Indrawati. (2014). Diplomasi Indonesia Terhadap Uni Eropa Dalam Penandatanganan Voluntary Partnership Agreement On Forest Law Enforcement Governance And Trade (Vpa-Flegt). Yogyakarta: Universitas Gadjah Mada.

Kementerian Kehutanan Badan Penyuluhan Dan Pengembangan Sdm Kehutanan Pusat Penyuluhan Kehutanan. (2011). Pendampingan Verifikasi Legalitas Kayu Rakyat, 2011. Jakarta: Kementerian Kehutanan .

Sianturi, A., \& Subarudi. (n.d.). Informasi Pasar: Standar Produk Kayu, Persyaratan Mutu Dan Peraturan Impor, Di Negara-negara Tujuan Ekspor Produk Kayu Indonesia. Jakarta: ISWA.

Sudharto, D. (2012, September 3). Kebijakan Dan Strategi SVLK Serta Sistem Pengakuannya Pengakuannya Dengan Negara-Negara Lain. Sosialisasi Svlk, Rpp B3 Dan Waste Paper. Jakarta.

\section{Website}

Kerjasama Asmindo dan WWF untuk Mendukung Implementasi SVLK. (2013, April 14). Retrieved Agustus 15, 2014, from Gerai Asmindo: http://geraiasmindo.com/?p=1181

Arifenie, F. N. (2013, Februari 28). Asia menjadi tujuan utama ekspor kayu Indonesia. Retrieved January 16, 2014, from Kontan: http://industri.kontsn.co.id/news/asia-menjadi-tujuan-utama-ekspir-kayuindonesia

EU response - FLEGT action plan. (n.d.). Retrieved from http://ec.europa.eu/development/policies/9interventionareas/environment/

European and Indonesian experts to inform. (2011). FLEGT Voluntary Partnership Agreement Between Indonesia and the European Union. jakarta: http://ec.europa.eu/europeaid/what/development-policies/interventionareas/environment/forestry_intro_en.htm. 
KJRI Hamburg. (2014, January 17). Sosialisasi SVLK Dorong Akses Pasar Lebih Luas di Eropa. Retrieved July 15, 2014, from Kemlu web site: http://www.kemlu.go.id/hamburg/Pages/Embassies.aspx?IDP=87\&l=id

Noviani, A. (2013, 11 5). ekspor produk kayu berdokumen tembus us5 miliar. Retrieved January 15, 2014, from bisnis.com: http://www.bisnisjateng.com/index.php/2013/11/ekspor-produk-kayu-berdokumen-tembus-us5miliar/

Prijono, A. (2013, Juni 6). Indonesia Tuntut Uni Eropa Segera Tanda Tangani VPA. Retrieved January 20, 2014, from National Geograpic Indonesia: http://nationalgeographic.co.id/berita/2013/06/indonesia-tuntut-uni-eropasegera-tanda-tangani-vpa

SILK. (2013, Oktober 17). RI-UE Resmi Tanda Tangani VPA. Retrieved Juli 15, 2014, from Kementerian Kehutanan Republik Indonesia: http://silk.dephut.go.id/index.php/article/vnews/28

WWF-Indo, Asmindo, GFTN, Uni Eropa. (2013, Maret 11). Lebih Dari 300 UKM Menuju Sertifikasi SVLK. Retrieved Juli 2014, from WWF Indonesia: http://www.wwf.or.id/?27520/Lebih-Dari-300-UKM-Menuju-SertifikasiSVLK

Yayasan Pusaka. (2014, Maret 7). Perkembangan FLEGT-VPA dan SVLK Di Indonesia. Retrieved Juli 15, 2014, from Yayasan Pusaka: http://pusaka.or.id/perkembangan-flegt-vpa-dan-svlk-di-indonesia/ 